\title{
Synthesis and photostabilizing performance of a polymeric HALS based on 1,2,2,6,6-pentamethylpiperidine and vinyl acetate
}

\author{
Marcelo Aparecido Chinelatto ${ }^{*}$, José Augusto Marcondes Agnelli² and Sebastião Vicente Canevarolo² \\ 'Departamento de Engenharia de Materiais, Universidade de São Paulo - USP, São Carlos, SP, Brasil \\ 2Departamento de Engenharia de Materiais, Universidade Federal de São Carlos - UFSCar, São Carlos, SP, Brasil \\ *mchinelatto@sc.usp.br
}

\begin{abstract}
Polymeric hindered amine light stabilizers (polymeric HALS) have been extensively studied because they combine a high ability to protect the polymers against harmful effects of weathering with minimum physical loss. In this study a new polymeric N-methylated HALS was synthesized by the radical copolymerization of a cyclic tertiary amine with vinyl acetate (VAc). 4-Acryloyloxy-1,2,2,6,6-pentamethylpiperidine (APP), the cyclic tertiary amine, was prepared by the initial conversion of 2,2,6,6-tetramethyl-4-piperidinol derivatives via two different routes. The APP/VAc copolymer synthesized was characterized by size exclusion chromatography (SEC), Fourier transform infrared spectroscopy (FTIR) and carbon-13 nuclear magnetic resonance $\left({ }^{13} \mathrm{C}\right.$ NMR). The photostabilizing performance, particularly the induction period of polypropylene (PP) films containing different concentrations of APP/VAc copolymer, when exposed to accelerated aging, was comparable to that of PP films compounded with commercial polymeric HALS.
\end{abstract}

Keywords: degradation, HALS, hindered amines, photo-oxidation, photostabilizer.

\section{Introduction}

Low stability against heat and ultraviolet (UV) radiation are considered the main limitations of polyolefins and hamper their use in several applications. Particularly when exposed to UV radiation and in the presence of oxygen, polyolefins undergo a photo-oxidative process, whose intensity can range from a superficial change, damaging the aesthetics of the product, to significant structural modifications, affecting their physical and mechanical properties ${ }^{[1,2]}$. The addition of hindered amine light stabilizers (HALS) to a polymer is the most effective way to stabilize it against UV radiation. HALS derivatives of 2,2,6,6-tetramethylpiperidine are blended into a large number of commercial polymers via extrusion process ${ }^{[3,4]}$. However the high temperatures and high shear rates used during the polymer extrusion may cause the volatilization of the low molecular weight HALS, significantly reducing their concentration and so their protection against photo-oxidation ${ }^{[5]}$.

Besides volatilization, other physical phenomena, such as compatibility with polymeric matrix and resistance to extraction by water and organic solvents during the end use also contribute to the reduction of the low molecular weight photostabilizers efficiency ${ }^{[6-8]}$. The synthesis of HALS of higher molecular weight by addition or condensation copolymerizations ${ }^{[9-11]}$ or the grafting of photostabilizers onto the preformed polymer ${ }^{[12-16]}$ are usual strategies described by the literature to eliminate or minimize such undesirable effects. The preparation of polymeric HALS by the copolymerization of hindered amines with ethylene or propylene is also an alternative route to reduce their physical loss ${ }^{[17,18]}$. Auer et al. ${ }^{[19]}$ described a novel and facile one-step synthetic route to prepare a HALS and its copolymerization with ethylene using a metallocene/methylalumoxane (MAO) as a catalyst system.

In a previous paper we studied the functionalization of 2,2,6,6-tetramethyl-4-piperidinol, a hindered amine by methyl acrylate and its subsequent radical copolymerization with vinyl acetate (VAc) and styrene (Sty) ${ }^{[20]}$. During the copolymerization the hydrogen atom bonded to the nitrogen in the piperidine ring was labile and reacted with propagating radicals. The high hindrance imposed by the four methyl groups on the radical formed in the nitrogen atom inhibited the formation of a new chemical bond with monomers whose pendant group has a large volume, as the case of Sty. The difficulty of establishing an effective chemical bond between nitrogen and Sty resulted in the formation of a soluble copolymer. However the pendant group in VAc would not be large enough to avoid the formation of an effective chemical bond whose radical is generated in the nitrogen atom, forming the crosslinked structure.

The undesired reactivity of the hydrogen bonded to the nitrogen in the hindered amine during the radical copolymerization could be overcome by the alkylation of N-H HALS. The photostabilizing effect of tertiary HALS, like N-alkyl HALS in polypropylene (PP) or polyethylene (PE) is comparable or superior to that of the parent secondary HALS $^{[21-23]}$. The mechanism by which N-methyl HALS inhibits a polymer oxidation involves the attack of $\mathrm{N}$-alkyl groups of tertiary HALS by oxidative active species, leading to its dealkylation and producing parent secondary HALS and carboxylic acid. The oxidation of this secondary amine leads to a stable nitroxyl radical. However other possible photostabilization mechanisms are the quenching 
of excited oxygen-polymer charge transfer complexes and hydroperoxides deactivation (CTC $)^{[21,24,25]}$.

In this paper the conversion of 2,2,6,6-tetramethyl-4piperidinol into APP was studied so as to enable its subsequent radical copolymerization with a vinyl monomer. The APP was prepared by two different routes involving the alkylation and functionalization of 2,2,6,6-tetramethyl-4-piperinol. The APP and intermediate compounds generated during the conversion of the piperidinol structure were characterized by FTIR and ${ }^{13} \mathrm{C}$ NMR. Subsequently a new polymeric HALS was synthesized via the radical copolymerization of APP with VAc and characterized by FTIR, ${ }^{13} \mathrm{C}$ NMR and SEC and its photostabilizing effectiveness was evaluated in PP films.

\section{Materials and Methods}

\subsection{Materials}

2,2,6,6-Tetramethyl-4-piperidinol (Aldrich, 98\%), acryloyl chloride (Aldrich, 96\%), triethylamine (Aldrich, 99\%), methyl acrylate (Aldrich, 99\%), methyl iodide (Aldrich 99\%) and titanium (IV) isopropoxide - Tipox (Aldrich, 97\%) were used as received. Vinyl acetate (Aldrich, 98\%) was used after distillation. Azo-bis-isobutyronitrile (AIBN), used as a thermal decomposition initiator, was kindly donated by Bayer from Brazil.

An isotactic PP was provided by Braskem S.A. (Brazil). According to the manufacturer, at a melt flow rate of $15 \mathrm{~g} 10 \mathrm{~min}^{-1}\left(230^{\circ} \mathrm{C} / 2.16 \mathrm{Kg}\right)$ this $\mathrm{PP}$ is considered a medium melt flow rate homopolymer with a general-purpose additive package, suitable for injection molding and fiber extrusion. The efficiency of the new polymeric HALS synthesized here to protect the PP films against photo-oxidation was compared with that of a commercial product Chimassorb 944 (HALS-1) - poly[[6-[(1,1,3,3-tetramethylbutyl)amino]1,3,5-triazine-2,4-diyl][(2,2,6,6-tetramethyl-4-piperidinyl) imino]-1,6-hexanediyl[(2,2,6,6-tetramethyl-4-piperidinyl) imino]] from Basf (Germany).

\subsection{Characterization}

The APP and the intermediate compounds generated during the alkylation and functionalization of piperidinol were characterized by FTIR using a Spectrum 1000 Spectrophotometer from Perkin-Elmer, at a $4000-400 \mathrm{~cm}^{-1}$ wavenumber range, with 24 scans for each spectra and $2 \mathrm{~cm}^{-1}$ resolution. The samples were dissolved in chloroform, cast over potassium bromide $(\mathrm{KBr})$ windows and dried under an infrared lamp.

The ${ }^{13} \mathrm{C}$ NMR spectra of 2,2,6,6-tetramethyl-4-piperidinol derivatives and APP/VAc copolymer were recorded on a Varian Unityplus 400 spectrometer operating at a $100.57 \mathrm{MHz}$ for the carbon- 13 nucleus using a $5 \mathrm{~mm}$ probe at room temperature. For quantitative measurements, the sample solutions $(250 \mathrm{mg} / 250 \mu \mathrm{L})$ were prepared in $\mathrm{CDCl}_{3}$. The experiments were performed in inverse gated decoupling mode. The parameter for these studies were $90^{\circ}$ pulse width $10 \mu \mathrm{s}$, relaxation delay $15 \mathrm{~s}$, acquisition time $0,68 \mathrm{~s}$ and 3.000 repetitive scans were taken for a good signal-to-noise ratio. The molar ratio of the monomers and the chemical composition of the copolymer were determined according to the procedure previously described ${ }^{[20]}$

The molecular weight distribution curve of the APP/VAc copolymer was determined by SEC on a Waters 510 Chromatograph with a refractive index detector using three Ultrastyragel linear columns. The calibration curves were plotted using twelve samples of monodisperse polystyrene standards, ranging from 480 to $1 \times 10^{6} \mathrm{~g} \mathrm{~mol}^{-1}$. Tetrahydrofuran was used as the solvent at a flow rate of $1.0 \mathrm{~mL} \mathrm{~min}^{-1}$ at room temperature. Molecular weights were determined by Milennium 2010 software.

\subsection{Preparation of APP}

The preparation of APP was performed by two different routes. In the first the APP was prepared by the alkylation of 4-acryloyloxy-2,2,6,6-tretamethylpiperidine (4ATP). Thus, firstly 4-acryloyloxy-2,2,6,6-tretamethylpiperidine (4ATP) was prepared by a transesterification reaction, according to the procedure previously described ${ }^{[20,26]}$. 4ATP ( $0.5 \mathrm{~g} ; 2.4 \mathrm{mmol})$, methyl iodide $(2.8 \mathrm{~mL} ; 45.2 \mathrm{mmol})$ and potassium carbonate $(0.28 \mathrm{~g} ; 2.0 \mathrm{mmol})$ were added in a single-neck flask reactor with a mixture of distilled water $(1.87 \mathrm{~mL})$ and chloroform $(4.69 \mathrm{~mL})$ according to the procedure described by Kurumada et al. ${ }^{[23]}$. The mixture was maintained under stirring for one week at room temperature. It was then poured into an aqueous ammonia solution and extracted with chloroform. The chloroform was dried with anhydrous potassium carbonate and evaporated under reduced pressure. The global yield of the APP prepared by this route was $5.5 \%$.

In the second route the alkylation of 2,2,6,6-tetramethyl4-piperidinol ( $0.5 \mathrm{~g} ; 3.2 \mathrm{mmol}$ ) was carried out by the same method described above and resulted in the formation of 1,2,2,6,6-pentamethyl-4-piperidinol (PPOl), a crystalline solid that cannot be polymerized by free radicals. In the functionalization of this tertiary cyclic amine, PPOl reacted with acryloyl chloride and triethylamine according to a procedure described in the literature ${ }^{[27]}$. The liquid obtained at the end of the reaction was also the APP. The final yield of APP was $12.5 \%$, being this higher yield the main advantage when the two routes are compared.

IR data APP $\left(\mathrm{cm}^{-1}\right): \mathrm{C}=\mathrm{O} 1733 ; \mathrm{C}=\mathrm{C} 1636 ; \mathrm{O}-\mathrm{C}(=\mathrm{O})-\mathrm{C}$ 1295; C-O 1064; N-CH 958.

${ }^{13} \mathrm{C}$ NMR APP (ppm): N-CH3 27.7; C-CH3 32.8; $>\mathrm{C}=\mathrm{O}$ 165.6.

\subsection{Synthesis of APP/VAc copolymer}

The APP/VAc copolymer, a polymeric N-methylated HALS, was prepared by free radical copolymerization, using toluene as the solvent. The AIBN concentration was $1.0 \mathrm{wt} \%$ by weight of the monomer mixture $\left(3.61 \times 10^{-2} \mathrm{mmol}\right)$, the molar ratio of APP to VAc was 1:6, and the mass ratio of the solvent to the monomers mixture was 2.5:1. The radical copolymerization was performed in a $250 \mathrm{~mL}$ flask containing the above-mentioned proportions of comonomers and toluene, under nitrogen atmosphere. The radical copolymerization of APP with VAc was carried out for 10 hours at $60^{\circ} \mathrm{C}$ and the polymer was reprecipitated in petroleum ether, collected and dried for 8 hours under vacuum at $40^{\circ} \mathrm{C}$. 


\subsection{Performance of APP/VAc copolymer in accelerated weathering}

\subsubsection{Preparation of the test samples}

The APP/VAc copolymer and a HALS-1 were dispersed in the PP by a hot dissolution process. A $250 \mathrm{~mL}$ glass beaker with $5.0 \mathrm{~g}$ PP and $50 \mathrm{~mL}$ of xylene was placed on a hot plate at $100^{\circ} \mathrm{C}$ and maintained at this temperature under stirring until the complete dissolution of the PP. Thereafter the respective amounts of HALS were added to the polymer solution. The heating and manual stirring were maintained until the complete evaporation of the solvent and the light-stabilized polymers were dried in a vacuum oven for 24 hours at $70^{\circ} \mathrm{C}$.

The samples were prepared with different concentrations of polymeric HALS in such a way that the equivalent piperidine functionality concentration kept constant. A comparison based on the equivalent functional concentration, i.e., equal nitrogen content of piperidine ring enables the proper evaluation of the HALS effectiveness with different molecular weights and structures ${ }^{[28]}$. Therefore the samples were prepared with the equivalent piperidine functionality concentrations of $0.093 \mathrm{~g} / \mathrm{Kg}$ PP and $0.140 \mathrm{~g} / \mathrm{Kg}$ PP.

PP films for FTIR spectral characterization were prepared by compression molding using a laboratory press set at $190^{\circ} \mathrm{C}, 10 \mathrm{MPa}$ pressure and compression time of $2 \mathrm{~min}$. Films for the accelerated weathering were selected having transmittance of $35 \pm 2 \%$ at $1170 \mathrm{~cm}^{-1}$. The absorption at $1170 \mathrm{~cm}^{-1}$ is ascribed to C-C stretch and proportional to the film thickness.

\subsubsection{Accelerated weathering exposure}

The photo-oxidation was performed using an Atlas Weather-Ometer model Ci65 equipped exclusively with xenon lamps, daylight filter and irradiance at $340 \mathrm{~nm}$ of $0.35 \mathrm{~W} / \mathrm{m}^{2} . \mathrm{nm}$. The exposure conditions were $102 \mathrm{~min}$ light at $63^{\circ} \mathrm{C}$ (black panel temperature) and 18 min light and water spray. A new sample was withdrawn every 100 hours of exposure and did not return to the Weather-O-Meter.

The photo-oxidation of the PP films was monitored by an FTIR spectrophotometer (Spectrum 1000, Perkin-Elmer) under the same conditions described above. To eliminate the influence of the film thickness on the absorption of the carbonyl groups, the normalized carbonyl index (CI) was calculated as the ratio of the absorption intensity at $1713 \mathrm{~cm}^{-1}$, due to the $\mathrm{C}=\mathrm{O}$ stretch, and $1170 \mathrm{~cm}^{-1}$ due to the $\mathrm{C}-\mathrm{C}$ stretch $\left(\mathrm{CI}=\mathrm{A}_{1713} / \mathrm{A}_{1170}\right)$. The evolution of the degradation process was evaluated by measuring the variation of the carbonyl index $\left(\mathrm{CI}_{\mathrm{t}}-\mathrm{CI}_{0}\right)$, where $\mathrm{CI}_{\mathrm{t}}$ is the normalized carbonyl index determined at time $\mathrm{t}$ and $\mathrm{CI}_{0}$ is the normalized carbonyl index before aging $(\mathrm{t}=0)$.

\section{Results and Discussions}

\subsection{Synthesis of APP/VAc copolymer}

The new polymeric HALS was synthesized by radical copolymerization, employing a 1:6 molar ratio of APP to VAc in the feed. The SEC results showed that the molecular weight distribution curve is monomodal, the number-average molecular weight $\left(\overline{M_{n}}\right)$ is $4,300 \mathrm{~g} \mathrm{~mol}^{-1}$ and polydispersity is 1.56 . The molecular weight in the range from 2,000 to $3,000 \mathrm{~g} \mathrm{~mol}^{-1}$ is suitable to guarantee that HALS will not leach out of the polymer ${ }^{[29]}$. Stabilizers whose molecular weight is higher than this range are usually more resistant to volatility or leaching out, but the increase in the molecular weight decreases their solubility and compatibility with the polymeric matrix. Gugumus studied the effect of molecular weight of polyacrylate HALS on the stabilization efficiency of the cast PP films and observed that the major drop in performance occurs if the molecular weight increases from 2,700 to $6,800 \mathrm{~g} \mathrm{~mol}^{-1[30]}$. The results also showed that even for very large molecular weights there remains some contribution of the HALS to UV stability, which increases with the increase in the HALS' concentration.

The APP/VAc copolymer was characterized by ${ }^{13} \mathrm{C}$ NMR and its spectrum is shown in Figure 1. The signals at $170.3 \mathrm{ppm}$ and $174.2 \mathrm{ppm}$ are due to the carbonyl carbons. The signal at $170.3 \mathrm{ppm}$ is assigned to the carbonyl carbon of the VAc because it is more shielded than the carbonyl carbon of the APP. The opening of the double $\mathrm{C}=\mathrm{C}$ bond of the APP during the copolymer synthesis causes a $165.6 \mathrm{ppm}$ to $174.2 \mathrm{ppm}$ displacement of the signal relative to the carbonyl carbon. The signals at $27.7 \mathrm{ppm}$ and $32.9 \mathrm{ppm}$ are related to carbons of the methyl groups bonded to carbon and nitrogen in the APP unit, respectively. The chemical shift at $18.7 \mathrm{ppm}$ is assigned to the carbon of the methyl group of the VAc.

The molar ratio of APP to VAc in the copolymer was determined by the ratio between the area of each sign and the number of nuclei responsible for the signal. Integrating the signal related to the carbons of methyl groups present in the chemical structures of the APP and VAc and dividing them by the number of nuclei responsible for each signal yielded a 1:2.5 molar ratio of APP to VAc in the copolymer. This molar ratio is higher than that of APP:VAc in the feed, i.e. 1:6, which indicates that the APP is more reactive than the VAc under polymerization conditions. Knowing the weight-average molecular weight $\left(\overline{M_{w}}\right)$ value and the molar ratio of APP:VAc in the copolymer and assuming that the molecular weights of APP and VAc are $225.3 \mathrm{~g} \mathrm{~mol}^{-1}$ and $86.1 \mathrm{~g} \mathrm{~mol}^{-1}$, respectively, the APP/VAc copolymer

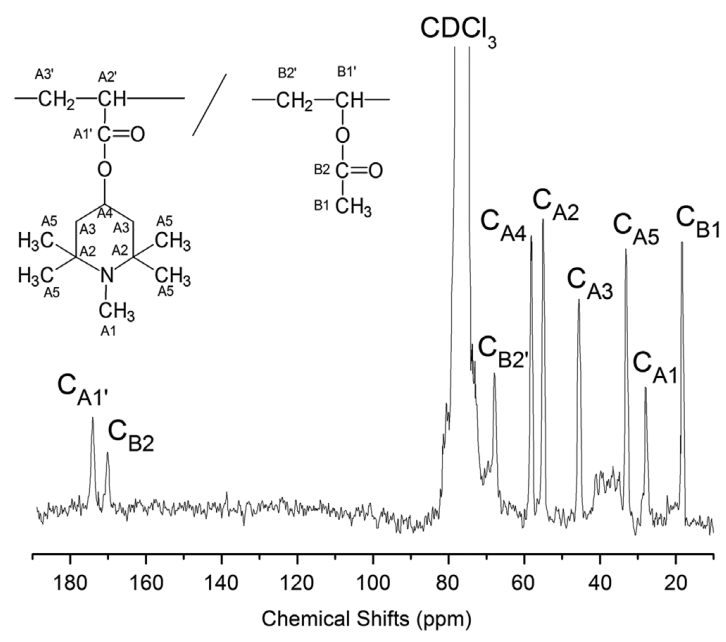

Figure $1 .{ }^{13} \mathrm{C}-\mathrm{NMR}$ spectrum of APP/VAc copolymer. 
is comprised of 15 units of APP and 38 units of VAc, on average. The results indicate that the polymeric HALS synthesized under this conditions is a statistical copolymer.

\subsection{Performance of APP/VAc copolymer in accelerated weathering}

The curves of the normalized carbonyl index (CI) as a function of the aging time of the PP films with and without polymeric HALS are shown in Figure 2. According to the literature these curves can be characterized by two distinct regions: in the first, known as induction period, the value of the normalized CI is zero, whereas in the other a rapid increase in the normalized CI is monitored, following a
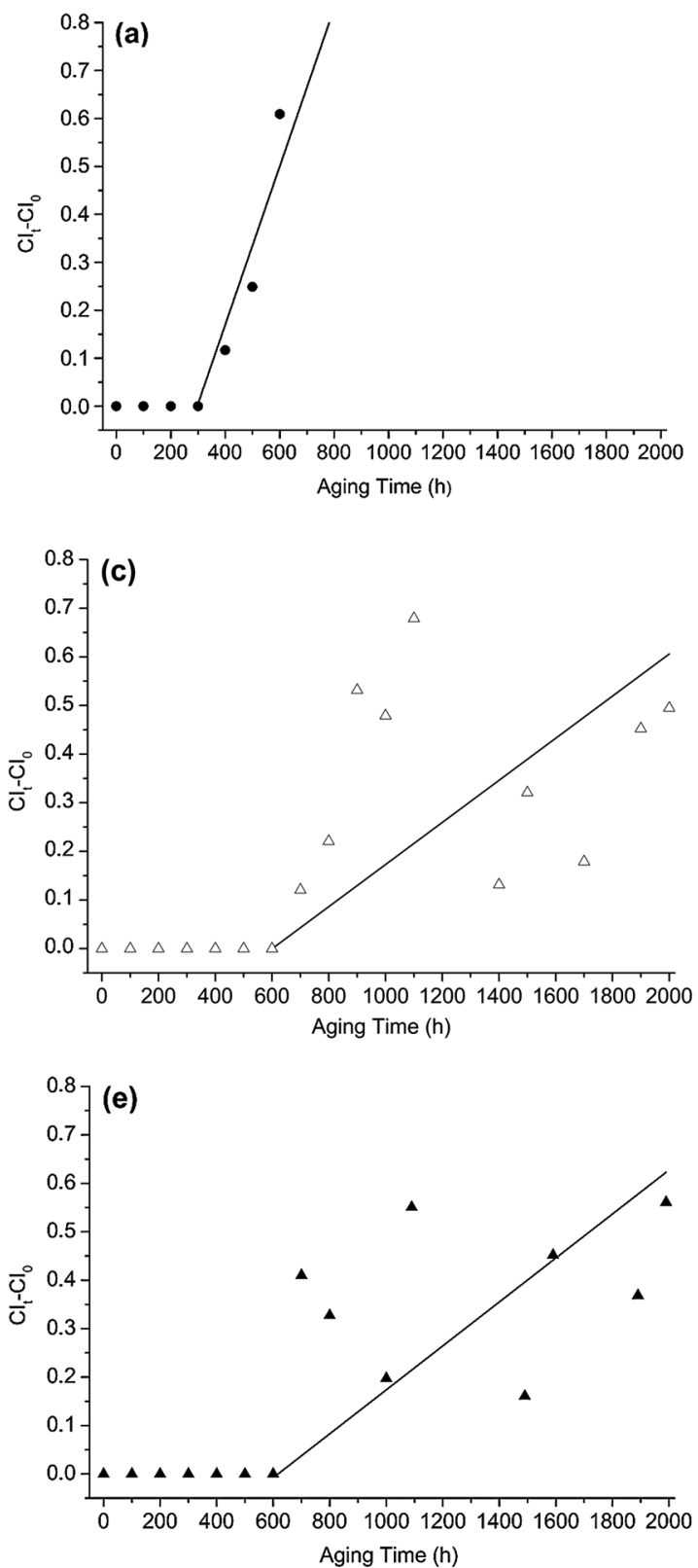

quasi-linear evolution ${ }^{[31]}$. Although it is clear that the curves in the Figure 2 showed a substantial dispersion of data, their behaviors were assumed to follow a linear correlation passing through the last point in the induction period.

Usually studies quantifying the evolution of the degradation process in polymers, applying non-destructive characterization methods, utilize the same set of samples that are removed from the aging environment, tested and returned back to further age and test again. In experiments carried out using this procedure, particularly FTIR measuring the normalized CI do show a quasi-linear relationship. Here a different film is tested each time and so greater data dispersion is expected. One reason could be attributed to the possible fractional
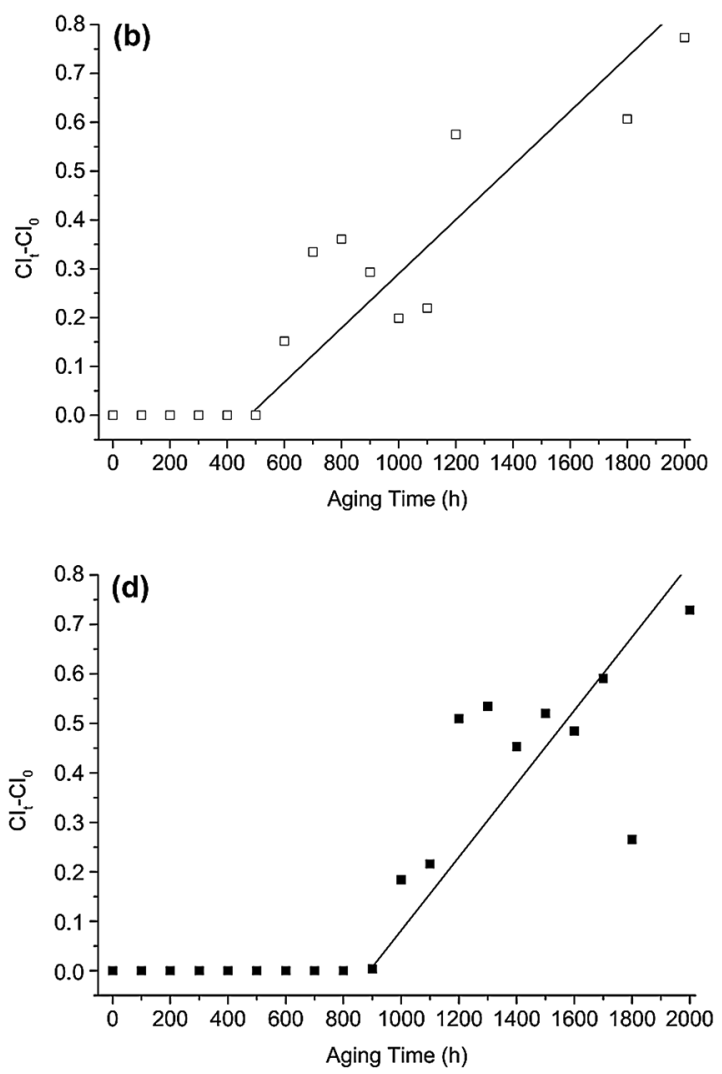

Figure 2. Normalized CI as a function of the aging time of PP films $-(\bullet)$ control; $(\square)[$ APP/VAc] $=0.093 \mathrm{~g} / \mathrm{Kg}$ PP; $(\Delta)[\mathrm{HALS}-1]=$ $0.093 \mathrm{~g} / \mathrm{Kg} \mathrm{PP} ;(\boldsymbol{\bullet})[\mathrm{APP} / \mathrm{VAc}]=0.140 \mathrm{~g} / \mathrm{Kg} \mathrm{PP}$ and $(\boldsymbol{\Delta})[\mathrm{HALS}-1]=0.140 \mathrm{~g} / \mathrm{Kg} \mathrm{PP}$. 
Table 1. Induction period and normalized CI of PP films under accelerated aging conditions.

\begin{tabular}{lccc}
\hline PP film & $\begin{array}{c}\mathbf{E E P F}^{\mathbf{a}} \\
\left(\mathbf{x 1 0 ^ { - 2 }} \mathbf{g} / \mathbf{K g} \mathbf{P P}\right)\end{array}$ & $\begin{array}{c}\text { Induction } \\
\text { Period }(\mathbf{h})\end{array}$ & $\mathbf{C I}_{\mathbf{t}}-\mathbf{C I}_{\mathbf{0}}$ \\
\hline Control & - & 300 & $0.6^{\mathrm{b}}$ \\
APP/VAc & 9.3 & 500 & $0.8^{\mathrm{c}}$ \\
& 14.0 & 900 & $0.8^{\mathrm{c}}$ \\
HALS-1 & 9.3 & 600 & $0.6^{\mathrm{c}}$ \\
& 14.0 & 600 & $0.6^{\mathrm{c}}$ \\
\hline
\end{tabular}

${ }^{a}$ Equivalent piperidine functionality concentration. ${ }^{b}$ Variation in the normalized $\mathrm{CI}\left(\mathrm{CI}_{t}-\mathrm{CI}_{0}\right)$ after $600 \mathrm{~h}$ under accelerated aging. ${ }^{c}$ Variation in the normalized $\mathrm{CI}\left(\mathrm{CI}_{\mathrm{t}}-\mathrm{CI}_{0}\right)$ after $2000 \mathrm{~h}$ under accelerated aging.

precipitation of the PP and polymeric HALS during the preparation of the films via cast from solution resulting in a less homogeneous distribution of the photostabilizer in the polymer matrix.

According to Figure 2a, the PP films without photostabilizers (control) showed low stability against the photo-oxidation given an induction period of only 300 hours. After that the rate of CI increase is quite high reaching already 0.6 at 600 hours of exposure to the accelerated weathering. Longer aging times produce PP films that are too brittle and the samples crack and crash easily, precluding the normalized CI to be measured. The PP films containing APP/VAc copolymer and HALS-1 as polymeric HALS showed a significant increase in the induction period in comparison with the control films. The induction periods of the PP films containing an equivalent piperidine functionality concentration of $0.093 \mathrm{~g} / \mathrm{Kg}$-PP of APP/VAc copolymer (Figure 2b) and HALS-1 (Figure 2c) were 500 hours and 600 hours, respectively, nearly twice those exhibited by the control films.

By increasing the equivalent piperidine functionality concentration of APP/VAc copolymer in PP films to $0.140 \mathrm{~g} / \mathrm{Kg}$-PP (Figure 2d), the induction period was further increased to 900 hours. However the increases in the nitrogen content of piperidine ring in the light-stabilized films with HALS-1 (Figure 2e) did not result in a longer induction period expected. The values of induction period and normalized carbonyl index after 2000 hours of exposure to the accelerated weathering of the PP films with and without photostabilizers are shown in Table 1.

The performance of the novel HALS proposed here reach values for the induction period close to the values shown by the referenced commercial compound. The protection of the new stabilizer at longer exposition times did show a lower performance, indicating its application mainly to items with shorter life cycles.

\section{Conclusions}

A new polymeric N-methyl HALS was synthesized by the radical copolymerization of 2,2,6,6-tetramethyl4-piperidinol derivatives with VAc. The N-substituted piperidinol derivatives were prepared via alkylation reaction with methyl iodide by two different routes. The alkylation of 2,2,6,6-tetramethyl-4-piperidinol and reaction of acryloyl chloride produced a final yield of $12.5 \%$, against $5.5 \%$ obtained by the alkylation of 4ATP, which is an important advantage of the second route. While dispersed in a PP matrix APP/VAc copolymer did protected it against the weathering environment showing similar performance in terms of induction period as a commercial polymeric HALS. Its application would include mainly protection to goods of low cycle life.

\section{Acknowledgements}

We express our acknowledgments for the invaluable collaboration of Elói J. Esmanhoto (in memoriam), the National Council for Scientific and Technological Development $(\mathrm{CNPq})$ for the financial support and the Institute of Technology for Development (LACTEC) for the accelerated weathering tests.

\section{References}

1. Andrady, A. L., Hamid, S. H., Hu, X., \& Torikai, A. (1998). Effects of increased solar ultraviolet radiation on materials. Journal of Photochemistry and Photobiology. B, Biology, 46(13), 96-103. http://dx.doi.org/10.1016/S1011-1344(98)00188-2. PMid:9894353.

2. Feldman, D. (2002). Polymer weathering: photo-oxidation. Journal of Polymers and the Environment, 10(4), 163-173. http://dx.doi.org/10.1023/A:1021148205366.

3. Rabek, J. F. (1995). Polymer photodegradation: mechanisms and experimental methods. London: Chapman \& Hall.

4. Ammala, A., Bateman, S., Dean, K., Petinakis, E., Sangwan, P., Wong, S., Yuan, Q., Yu, L., Patrick, C., \& Leong, K. H. (2011). An overview of degradable and biodegradable polyolefins. Progress in Polymer Science, 36(8), 1015-1049. http://dx.doi. org/10.1016/j.progpolymsci.2010.12.002.

5. Cáceres, C. A., Zborowski, L., \& Canevarolo, S. V. (2011). Thermo-mechanical degradation and voc emission of unstabilized and stabilized polypropylene copolymer during multiple extrusion. Materials Research, 14(4), 569-575. http://dx.doi. org/10.1590/S1516-14392011005000081.

6. Minagawa, M. (1989). New developments in polymer stabilization. Polymer Degradation \& Stability, 25(2-4), 121141. http://dx.doi.org/10.1016/S0141-3910(89)81004-3.

7. Smoliak, L. Y., \& Prokopchuk, N. R. (2003). Estimation of parameters that correlate molecular structure of hindered amines with their stabilizing efficiency. Polymer Degradation \& Stability, 82(2), 169-172. http://dx.doi.org/10.1016/S01413910(03)00180-0.

8. Malík, J., Hrivík, A., \& Alexyová, D. (1992). Physical loss of hindered amine light stabilizers from polyethylene. Polymer Degradation \& Stability, 35(2), 125-130. http://dx.doi. org/10.1016/0141-3910(92)90103-C.

9. Pan, J. (2001). Synthesis and characterization of new stabilizers with optimal molecular weight. Chinese Journal of Polymer Science, 19(4), 341-350.

10. Jiangqing, P., Cheng, W., Song, Y., \& Hu, X. (1993). Preparation and characterization of new copolymers containing hindered amine. Polymer Degradation \& Stability, 39(1), 85-91. http:// dx.doi.org/10.1016/0141-3910(93)90128-6.

11. Sun, G. J., Jang, H. J., Kaang, S., \& Chae, K. H. (2002). A new polymeric hals: preparation of an addition polymer of dgeba-hals and its photostabilizing effect. Polymer, 43(22), 5855-5863. http://dx.doi.org/10.1016/S0032-3861(02)00514-1.

12. Wang, H., \& Chen, W. (2006). Radiation-induced grafting of binary monomers containing hals onto polymers. Radiation Physics and Chemistry, 75(1), 138-148. http://dx.doi.org/10.1016/j. radphyschem.2005.04.022. 
13. Wang, H. (2005). Radiation-induced grafting of pentamethyl hindered amine light stabilizer 1,2,2,6,6-pentamethyl-4piperidinyl methacrylate onto polypropylene. Journal of Applied Polymer Science, 98(5), 2157-2164. http://dx.doi. org/10.1002/app.22388.

14. Cicogna, F., Coiai, S., Passaglia, E., Tucci, I., Ricci, L., Ciardelli, F., \& Batistini, A. (2011). Grafting of functional nitroxyl free radicals to polyolefins as a tool to postreactor modification of polyethylene-based materials with control of macromolecular architecture. Journal of Polymer Science. Part A, Polymer Chemistry, 49(3), 781-795. http://dx.doi. org/10.1002/pola.24493.

15. Kaci, M., Touati, N., Setnescu, R., Zaharescu, T., Setnescu, T., \& Jipa, S. (2005). Grafting of hindered amine stabilizer in poly(propylene) films under $\gamma$-irradiation. Macromolecular Materials and Engineering, 290(8), 802-808. http://dx.doi. org/10.1002/mame.200500096.

16. Singh, R. P., Patwa, A. N., Desai, S. M., Pandey, J. K., Solanky, S. S., \& Vishwa Prasad, A. (2003). Synthesis of new polymeric hindered amine light stabilizers: performance evaluation in styrenic polymers. Journal of Applied Polymer Science, 90(4), 1126-1138. http://dx.doi.org/10.1002/app.12672.

17. Yang, H., \& Lü, Q. (1997). Copolymerization of propylene with hindered piperidine monomer over a high activity supported ziegler-natta catalyst. Chinese Journal of Polymer Science, 15(2), 146-153.

18. Wilén, C. E., Auer, M., Strandén, J., Näsman, J. H., Rotzinger, B., Steinmann, A., King, R. E., Zweifel, H., \& Drewes, R. (2000). (20002). Synthesis of novel hindered amine ligh stabilizers (hals) and their copolymerization with ethylene or propylene over both soluble and supported metallocene catalyst systems. Macromolecules, 33(14), 5011-5026. http:// dx.doi.org/10.1021/ma0000780.

19. Auer, M., Nicolas, R., Vesterinen, A., Luttikhedde, H., \& Wilén, C. E. (2004). Facile synthetic route to polymerizable hindered amine light stabilizers for transition-metal-catalyzed olefin copolymerization. Journal of Polymer Science. Part A, Polymer Chemistry, 42(6), 1350-1355. http://dx.doi.org/10.1002/ pola.11082.

20. Chinelatto, M. A., Agnelli, J. A. M., \& Canevarolo, S. V. (2014). Synthesis and characterization of copolymers from hindered amines and vinyl monomers. Polímeros, 24(1), 30-36. http:// dx.doi.org/10.4322/polimeros.2014.046.

21. Gugumus, F. (1991). Mechanisms and kinetics of photostabilization of polyolefins with n-methylated hals. Polymer Degradation \& Stability, 34(1-3), 205-241. http://dx.doi.org/10.1016/01413910(91)90120-G.
22. Gugumus, F. (1993). Current trends in mode of action of hindered amine light stabilizers. Polymer Degradation \& Stability, 40(2), 167-215. http://dx.doi.org/10.1016/0141-3910(93)90208-Z.

23. Kurumada, T., Ohsawa, H., Oda, O., Fujita, T., Toda, T., \& Yoshioka, T. (1985). Photostabilizing activity of tertiary hindered amines. Journal of Polymer Science: Polymer Chemistry Edition, 23(5), 1477-1491. http://dx.doi.org/10.1002/ pol.1985.170230520.

24. Gijsman, P. (2010). Photostabilization of polymer materials. In N. S. Allen (Ed.), Photochemistry and photophysics of polymer materials (pp. 627-679). New Jersey: John Wiley \& Sons.

25. Pospišsil, J., Pilař, J., \& Nešpůrek, S. (2007). Exploitation of the complex chemistry of hindered amine stabilizers in effective plastics stabilization. Journal of Vinyl and Additive Technology, 13(3), 119-132. http://dx.doi.org/10.1002/vnl.20113.

26. Al-Malaika, S., Scott, G., \& Wirjosentono, B. (1993). Mechanisms of antioxidant action: polymer-bound hindered amines by reactive processing, part III effect of reactive antioxidant structure. Polymer Degradation \& Stability, 40(2), 233-238. http://dx.doi.org/10.1016/0141-3910(93)90210-A.

27. Al-Malaika, S., Ibrahim, A. Q., \& Scott, G. (1988). Mechanisms of antioxidant action: photo-antioxidant activity of polymerbound hindered amines. part I-bismaleate esters. Polymer Degradation \& Stability, 22(3), 233-239. http://dx.doi. org/10.1016/0141-3910(88)90013-4.

28. Pan, J., Yang, Z., Zhang, T., Lau, W. W. Y., \& Lee, C. S. (1994). A comparative study of monomer, homopolymer and copolymer hals. Polymer Degradation \& Stability, 44(1), 85-91. http:// dx.doi.org/10.1016/0141-3910(94)90037-X.

29. Gijsman, P., Smelt, H. J., \& Schumann, D. (2010). Hindered amine light stabilizers: an alternative for radiation cross-linked uhmwpe implants. Biomaterials, 31(26), 6685-6691. http:// dx.doi.org/10.1016/j.biomaterials.2010.05.053. PMid:20619782.

30. Gugumus, F. (2000). Aspects of the impact of stabilizer mass on performance in polymers 2 . Effect of increasing molecular mass of polymeric HALS in pp. Polymer Degradation \& Stability, 67(2), 299-311. http://dx.doi.org/10.1016/S01413910(99)00131-7.

31. Philippart, J. L., Sinturel, C., \& Gardette, J. L. (1997). Influence of light intensity on the photooxidation of polypropylene. Polymer Degradation \& Stability, 58(3), 261-268. http://dx.doi. org/10.1016/S0141-3910(97)00056-6.

Received: Jan. 12, 2015

Revised: May 07, 2015

Accepted: Aug. 10, 2015 